\title{
Prednisone for Cardiac Failure in Patients with Hypertension
}

In this issue of The Journal, Meng, et al present evidence for the effectiveness of prednisone for treating symptomatic Stage 3 or Stage 4 cardiac failure in patients with hyperuricemia ${ }^{1}$. Prednisone doses were according to clinician choice, but the basis for these choices, ranging from $10 \mathrm{mg}$ to $60 \mathrm{mg} / \mathrm{day}$, is unclear. Many rheumatologists might wish to prescribe prednisone to treat the distressing symptoms of acute gout in such patients but would hesitate because of concerns that the heart failure would worsen because of an increase in blood pressure ${ }^{2}$. The authors propose that the amelioration of the symptoms of heart failure is the result of an enhanced response to diuretics suggested by the brisk diuresis that ensued. Inter alia, serum uric acid and creatinine concentrations fell significantly, by $2.99 \mathrm{mg} / \mathrm{dl}(264 \mu \mathrm{mol} / \mathrm{l})$ and $0.16 \mathrm{mg} / \mathrm{dl}(9.52 \mu \mathrm{mol} / \mathrm{l})$, respectively, and a significant diuresis was induced. These data suggest that perhaps we could relax our negative attitude to corticosteroid treatment of acute gout in patients with significant heart failure, especially when alternative approaches are problematic.

Beyond the obvious diuresis that followed commencement of treatment, the mechanism for this effect of prednisone is uncertain. The authors speculate that because renal inflammation is a prominent component of widespread inflammation in these patients, the potent antiinflammatory action of prednisone is the likely mechanism for the diuresis and improvement in the symptoms of cardiac failure.

The authors reasonably suggest that their retrospective, longitudinal, uncontrolled, observational examination of 191 patients in their institution demands a prospective randomized, placebo-controlled trial. These researchers have previously shown that prednisone was a potent diuretic in stable heart failure patients with overt fluid retention ${ }^{3}$. This effect they considered was likely due to dilation of renal medullary vasculature mediated by increased response to atrial natriuretic peptide. It would be instructive to examine how dependent the diuretic effect of prednisone is upon concomitant diuretics in patients with heart failure in the current study.

The patients in the current study were not stable but decompensated with acute-on-chronic heart failure. The authors argue that inflammation plays a significant role in the acute cardiac deterioration and that raised uric acid in these patients contributes to this process. The authors imply that the reduction in plasma urate seen with prednisone treatment is instrumental in reducing the inflammatory process that contributed to the cardiac deterioration. More plausibly, the compromised cardiac output led to reduced glomerular filtration, and as renal function improved, urate concentrations fell as expected. An aspect of Meng, et al's article that is unclear is whether the dose of frusemide (furosemide) needed in these patients remained stable as the urate fell ${ }^{1}$. Frusemide dose reduction that may have occurred as patients improved will also be associated with a fall in plasma urate concentrations $s^{4,5,6}$.

From a rheumatology perspective, it is true that attacks of gout are common in people presenting with acute-on-chronic heart failure (and other stressful, acute medical and surgical conditions). Nonsteroidal antiinflammatory drug (NSAID) therapy is commonly contraindicated because of the propensity of NSAID to impair renal function, increase blood pressure, and precipitate cardiac failure, all more common in the elderly ${ }^{7}$. Colchicine is an unattractive option for acute gout in these situations because of retention of the drug in renal impairment. Intraarticular corticosteroid therapy can be difficult if multiple joints are involved.

The safety of using prednisone in decompensated Stage 3 and Stage 4 heart failure is not established by this uncontrolled study, and the drug is not recommended to treat cardiac failure ${ }^{8}$. The study findings indicate the need for a prospective, randomized, double-blind, placebo-controlled study. Given the well-known adverse effects of glucocorticosteroids, careful attention to safety will be essential.

RICHARD O. DAY, MD, FRACP,
Clinical Pharmacology,
St. Vincent's Hospital Sydney,
Darlinghurst, New South Wales, Australia.
Address correspondence to Dr. Day; E-mail: R.Day@unsw.edu.au

REFERENCES

1. Meng H, Liu G, Zhai J, Zhen Y, Zhao Q, Zheng M, et al.

See Prednisone for hyperuricemia in heart failure, page 866

Personal non-commercial use only. The Journal of Rheumatology Copyright $\subset$ 2015. All rights reserved. 
Prednisone in uric acid lowering in symptomatic heart failure patients with hyperuricemia PUSH-PATH3 - a retrospective cohort study. J Rheumatol 2015;42:866-9.

2. Whitworth JA, Gordon D, Andrews J, Scoggins BA. The hypertensive effect of synthetic glucocorticoids in man: role of sodium and volume. J Hypertens 1989;7:537-49.

3. Liu C, Liu K. Effects of glucocorticoids in potentiating diuresis in heart failure patients with diuretic resistance. J Card Fail 2014;20:625-9.

4. Ramsay LE, McInnes GT, Hettiarachchi J, Shelton J, Scott P. Bumetanide and frusemide: a comparison of dose-response curves in healthy men. Br J Clin Pharmacol 1978;5:243-7.

5. Stamp LK, Merriman TR, Barclay ML, Singh JA, Roberts RL, Wright DF, et al. Impaired response or insufficient dosage? Examining the potential causes of "inadequate response" to allopurinol in the treatment of gout. Semin Arthritis Rheum 2014;44:170-4.

6. Kannangara DR, Graham GG, Williams KM, Day RO.

Hypouricemic effects of prednisone and allopurinol: an uneven playing field? Can J Cardiol 2014;30:376.e1

7. Day RO, Graham GG. Nonsteroidal antiinflammatory drugs (NSAIDS). BMJ 2014;346:f3195.

8. McMurray JJ, Adamopoulos S, Anker SD, Auricchio A, Böhm M, Dickstein K, et al. ESC guidelines for the diagnosis and treatment of acute and chronic heart failure 2012 of the European Society of Cardiology. Developed in collaboration with the Heart Failure Association (HFA) of the ESC. Eur J Heart Fail 2012;14:803-69.

J Rheumatol 2015;42:739-40; doi:10.3899/jrheum.150276 